\title{
Putting Our Words to Work: Rethinking Teacher Talking Time
}

\section{SHELLY BARUA}

A teacher that already has experience in teaching English should recognize the ways in which teaching skills can be adapted for the teaching of in the classroom. Teachers have to set learning goals and then transform them into an instructional program with the timing of activities. One of the main tasks will be selecting, designing and organizing course materials, supporting the students in their efforts, and providing them with feedback on their progress. Teachers' knowledge of students' potentials is central in designing a syllabus with realistic goals that takes into account the students' concern in the learning situation. What is the role of the learner and what is the task he/she faces? The learners come to the class with a specific interest for learning, subject matter knowledge, and well-built adult learning strategies. The development of Communicative Language Teaching (CLT) brought with it a methodology which emphasized communication in the classroom, pair and group activities and student involvement in the learning process. A consequence of this was the belief that the teacher's presence in the classroom should be reduced.

\section{There are five main arguments against it:}

I. A large amount of Teacher Talking Time necessarily limits the amount of STT (student talking time). For example, in a 60 minute class, if the teacher is talking for a total of 45 minutes, that leaves only fifteen minutes left for the students. If there are ten in the class, they'll get only 90 seconds each to speak. Many activities, however, 
do not need to be teacher led - pair work (PW) or group work (GW) can be used instead. A practice activity might be set up in teacherto-class ( $\mathrm{T} /$ class) mode, demonstrated in open pairs (students doing the activity in front of the class), and done in closed pairs (all the students working at the same time).

II. A large amount of Teacher Talking Time inevitably means long stretches of time in teacher -to-class mode. This is uninvolving for students and is likely to lead to a drop in concentration and in pace. The lesson becomes boring and students "switch off". To prevent this, activities and interaction patterns (teacher to class mode, Pair Work, Group Work, Individual Work) need to be varied. How much class time can usefully be spent in T/class mode will depend on factors such as the students, the time of day, and what is being taught, but a useful rule of thumb guide is to set an absolute maximum of $30 \%$ of any one lesson, and no more than 10 minutes at a stretch.

III. TTT often means that the teacher is "telling" the students things that they could be working out for themselves - for instance grammar explanations and corrections. Apart from the fact that concentration may well wander half way through the explanation, monologue gives the teacher no real clue as to whether the students have understood. This can be avoided by using elicitation rather than explanation - the teacher asks pointer questions rather than simply telling, allowing the students to formulate the rules for themselves. If students are presented with clear examples and guiding questions, they often do not need to be "told". Discovering grammar in this way is liable to mean deeper understanding and ultimately more successful learning. Organising the activity as pair work rather than $\mathrm{T} /$ class work also means that all the students have 
the chance to work on the new language, and not just the quicker ones who get the answer immediately and "tell" the others.

IV. The work done by researchers such as Coulthard and Brazil $(1977,1980)$ on discourse analysis made it clear that T/S discourse is always distorted by the role imbalance of teacher and student - the teacher is expected to take the lead in initiating the topic, allocating turns, evaluating comments etc, while the student merely responds.

V. If the teacher is constantly dominant and controlling, student autonomy is minimized. Students take no responsibility for their own learning but learn what the teacher decides and when. Several methodologies of the last twenty five years or so have questioned whether this sort of "imposed syllabus" can produce results and have attempted to turn the situation on its head, giving learners full responsibility for the language produced and analysed in the classroom.

Is TTT always counterproductive? However, in the second part of this article we'll look at when it can be useful, and ways it can be used productively in the class.

In an experiment done by Roger Hunt we all learn our first language partly by listening to it and making sense, eventually, of what we heard. Most of what we heard was our parents speaking to us ie: Parent Talking Time (PTT). Clearly there are many other factors involved in first language acquisition, and many more in second language learning by adults, than just making sense of what we hear, but, that which we hear and make sense of remains a singularly powerful learning and teaching factor; perhaps a very underrated teaching tool. TTT may be divided into two main types: asking questions and saying things ie: making statements. The 
following is an account of helping teachers in training aware of their TTT as a teaching tool; a contributing factor in their learners' understanding and learning of a second language.

\section{Teachers and question types}

\section{Background}

In 1994 a candidate on what is now the Cambridge DELTA course conducted an experiment in which he recorded himself teaching and analyzed his TTT according to criteria developed by David Nunnan (1987). These criteria related to question types, which were: 'Display' questions, in which the teacher asks students to 'display' their knowledge of language eg: asking: 'What colour is my shirt?' in order to ascertain whether or not the student knows the appropriate vocabulary item, and 'Reference' questions to which the teacher does not know the answer eg: 'What did you do at the weekend?'. The Diploma candidate added two other criteria to his analysis which were:

\section{Purpose}

Why was the question asked in the first place?

\section{Linguistic Demand}

How much did the student have to say in order to answer the question? eg: a 'Yes/No' question requires very little in terms of language production from the student, whereas a question such as 'What did you do this weekend?' might demand much more (although I have worked with some students who are adept at giving a minimalist answer to this question eg: 'I sleep'!). 
The 'Purpose' analysis was intended to see to what extent the use of questioning was procedural ie: pertaining to the management of the class and lesson, and to what extent it was 'communicative' ie: using questioning to discover something not already known by the questioner. The 'Linguistic Demand' analysis was intended to see to what extent the students were invited to take long, as opposed to short, turns. In other words how much they were invited to contribute linguistically during the lesson; how much time they were given to practise speaking English. (This following Nunnan's suggestion (1987) that longer turn taking contributes to greater proficiency in second language usage.)

The results of this analysis were: the students were predominantly asked display questions, (which seemed to have little or no purpose), and the majority of the questions required little more than a nod or shake of the head by way of answer.

Following this analysis the candidate, for reasons of his own, resolved to eliminate all display questions and all questions which required a short turn response from his teaching.

\section{A continuing experiment by Roger Hunt}

As well as asking many teachers in training to record and evaluate their TTT, Roger Hunt, in his continuing experiment, have asked them to further their analysis by introducing other criteria for inclusion. These include: 'Waiting Time' ie: the length of time the teacher waits for a response having asked a question; 'Authenticity' ie: a question may be 'procedural' in as much as it is an aspect of classroom management eg: giving instructions/checking understanding/etc. or it may be genuine piece of communication eg: 'What did you think of the new Harry Potter film?' This 
differentiation may seem very similar to that between 'display' and 'reference' questions. However, the distinction here is that between classroom management (procedural) issues and those which the students may understand as 'real' (or 'Reference') questions. For example 'Could you open your books at page 17?' is unlikely to be seen by anyone as anything other than a procedural question.

\section{Waiting time}

Typically the teacher asks a question, waits for a second or two, feels undermined by the lack of an answer, then asks another question or gives the answer him/herself. Roger Hunt in his experiment asked the participants on an INSET training programme to ask a question then wait, however long it took for an answer from the students. One teacher in the training programme asked the question: 'What is the difference in meaning between 'walk' and 'run'. Seventeen seconds later a student offered an answer. Meanwhile the teacher sat silently. The other students in the room did not agree with the answer ('running is quicker than walking') and eventually decided that when walking one foot is always on the ground, whereas when running both feet are off the ground at times - a series of leaps. The interesting thing was that the teacher waited, he knew the answer to his question, but he knew that thinking time was involved and that rehearsal time was involved as well: thinking time to come up with an answer; rehearsal time to work out how to give the answer in a foreign language. Wisely perhaps, he waited: it is easy to answer questions such as 'How are you?' 'Fine', or 'Do you smoke?', but many questions which require longer turn-taking also require thinking and rehearsal time. This waiting time became an integral part of the continuing experiment. It also gave rise to the issue of the 'right to silence', in which students are not required to say anything until they want to do so. 


\section{Authenticity: Initiation Response Feedback (IRF)}

IRF is a well known phenomenon: the teacher asks a seemingly genuine question eg: 'What did you do last night?', the student responds eg: 'I went to the cinema.' then the teacher comments on their langauge display eg: 'Good!' (meaning: Good, you got the grammar etc right), the student then says: 'No'. What is going on here in the student's mind is not a comment on his/her language display but a genuine piece of communication, obviously the intended meaning was: 'No, it wasn't a good film.'.

A variant on this might be:

T: What did you do last night?

S: I've been to cinema.

T: Is that right?

S: Yes.

Again the teacher's response has been to question the correctness of the student's grammar etc., but this is not what the student has understood: the student is still communicating at the level of one human being to another. Clearly teachers need to help students say what they want to say correctly (phonologically, grammatically, lexically etc) but the above IRF sequences beg the issue of when it might be most appropriate to comment on language display and when it might be better to remain a human being engaging in conversation (and storing up the language display issue for later lessons?).

\section{The right to silence}

The issue of waiting time, particularly, leads to the issue of whether or not a student may be ready to contribute in class, and to the issue 
of whether or not a teacher should require a student to contribute. Clearly some students contribute even before invited (or welcome!) to do so, others are more reticent. Krashen (1981) suggested that contributions by students are only indications of what language they have acquired, rather than indications of what language they are acquiring.

The issue in the continuing experiment was to what extent a teacher might ask/require a student to contribute and to what extent did contributions by students indicate their ability with the foreign language. After all, many people are very quiet in their own languages though they have an expert mastery of it.

The continuing experiment, therefore, asked participants not to nominate individuals, but wait until any individual appeared to want to contribute. (An aside: Roger Hunt once watched a horrific lesson in which the teacher continually asked a particular student to contribute when she was not ready to do so: she found the pronunciation of the language point impossible. Rather than helping her, the teacher relied on showing her that all the other students, of different language backgrounds, could do it, therefore, so could she. She finished the lesson in tears.)

\section{Making Statements}

The human voice had an acknowledged role in second language learning many years before the present. In fact documentation on natural approaches, in which the prime source of 'input' is the teacher's voice abounds. The secret is merely to be aware of what the teachers are saying: the words they use; the way they pronounce connected speech, and the extent to which they help their learners become aware of these factors. 
So, based on all the above discussion we can clearly identify the following reasons for reducing TTT

- Excessive TTT limits the amount of STT (student talking time). If the teacher talks for half the time in a 60 minute lesson with 15 students, each student gets only 2 minutes to speak.

- A large amount of TTT results in long stretches of time in teacher-to-class (T/class) mode and a monotonous pace. Student under involvement inevitably leads to loss of concentration, boredom and reduced learning.

- TTT often means that the teacher is giving the students information that they could be finding out for themselves, such as grammar rules, the meanings of vocabulary items and corrections. Teacher explanations alone are often tedious, full of terminology and difficult to follow. There may be no indication of whether the students have understood.

- If the teacher takes the dominant role in classroom discourse in terms of initiating the topic, allocating turns and evaluating comments, the student's role is only that of respondent. Opportunities for developing the speaking skill are therefore severely limited.

- If the teacher is constantly dominant and controlling, the learners take no responsibility for their own learning but learn what the teacher decides and when. Student autonomy is thus limited.

\section{Strategies for reducing TTT}


The over-use of TTT is often the product of the under-use of communicative techniques in the classroom. Many activities do not need to be teacher led - pair work (PW) or group work (GW) can be used instead. An activity might be set up in T/class mode, demonstrated in open pairs (students doing the activity across the class), and done in closed pairs (all the students working at the same time). Some mechanical activities need to be done individually (IW) but can be checked in pairs. What is most important is that activities and interaction patterns (T/class, PW, GW, IW) need to be varied. The amount of time spent in $\mathrm{T} /$ class mode will depend on factors such as the students and how much they know, the stage of the lesson, the time of day and what is being taught, but a useful guideline is a limit of $30 \%$ of a lesson, and no more than 10 minutes at one time.

Other common strategies for reducing TTT include:

- Using elicitation rather than explanation. If students are presented with clear examples and guiding questions, they often do not need to be "told". This kind of guided discovery leads to better understanding and more successful learning. Organising activities as pair work also means that all the students have the chance to work on the new language.

- The use of body language, mime, gestures and facial expressions rather than words. The position of the teacher in the classroom can also indicate to the students what is expected of them at a particular stage of the lesson.

- Getting students to give feedback on tasks to each other rather than to the teacher. This is often done in pairs, but answers can also be checked against a key. Student nomination, whereby 
one student nominates another to answer a question, is also a useful technique. Feedback involving the teacher is therefore limited to problematic questions rather than every question in an exercise.

- Eliminating unnecessary TTT. Grading language is important, but over-simplification can lead to unnatural models from the teacher. Instructions should be kept simple, while explanations need to be carefully worded and repeated if necessary rather than paraphrased. Simple concept questions should be asked to check understanding. If explanations are clear and concept checking is effective, there should be no need for re-explanation or interrupting an activity to reteach or re instruct.

- Tolerating silence. Inexperienced teachers in particular tend to fill silences by unnecessary talking. Silence is important not only when students are working individually, but also provides 'processing time' between instructions, during explanations, while waiting for a student to respond, and during monitoring of activities. Prompting, providing clues and rephrasing the question are often counterproductive when the student merely needs time to answer.

\section{Positive uses of TTT}

In recent years, approaches other than CLT have suggested that TTT may not always be counterproductive and can be used to good effect. The teacher provides good listening practice which is not inhibited by the sound quality of a tape or CD player and which is accompanied by visual clues to aid comprehension. In a monolingual teaching context overseas, the teacher may provide a valuable source of authentic listening, exposing learners to a limited 
amount of new language, and 'roughly tuning' input to assist comprehension. In some circumstances, the teacher may be the only source of models of good, natural language. Some forms of TTT are clearly beneficial:

- Personalised presentations. Language should be presented in context, whether it is in Bangladesh or elsewhere in the world and whether the native language is English or not, and this can be provided by the teacher rather than through a reading or listening. Listening to the teacher talking about real issues is more motivating than listening to or reading about complete strangers talking about people, places or events which, for the students, have no personal interest. Students are also more likely to pick up knowledge which is content rather than language based by listening to the teacher introducing a topic.

- Questioning. Every teacher demands a student's response after a question is asked during a lesson. Questions need not be language related, and are often the basis of 'brainstorming' a topic with the class. Frequent questioning holds students' attention and increases learner involvement in the class.

- Natural conversation. Conversations taking place during pair and group work are often loaded towards certain language items or based on an imposed theme. Natural conversation initiated by the teacher encourages questioning, asking for clarification, commenting and changing the subject as well as introducing functional and everyday language which is often overlooked in course materials. It may be practiced in English and native language. Chats outside the classroom are also valuable and often more memorable to students than lessons. In these circumstances, teachers may use graded but natural 
language rather than to use simplified language to ensure understanding. This may take place during their counseling hours and also while they are involved in extra curricular activities and work in different forums.

- Anecdotes. These can be the basis of a presentation, but can also be used at the start of a lesson, rather than using a 'warmer' activity, as a natural way of engaging the students. Anecdotes and jokes may also be used to stimulate interest during a lesson. Anecdotes do not need to be monologues, and students can be encouraged to interrupt and ask questions.

- Storytelling. This can be the basis of a lesson or an ongoing theme throughout a course and is as appropriate to adult classes as it is to young learners. There is a whole methodology surrounding storytelling, which is often a stimulating alternative to the use of a graded reader in the classroom.

\section{Conclusion}

There are advantages and disadvantages to TTT. It is not easy to reduce TTT when talking to the students is a natural thing to do and when there is inevitably a theatrical side to language teaching. In certain cultures, there is also a tradition of 'chalk and talk' which influences the expectations and behavior both teachers and students. However, bearing in mind the nature of the communicative classroom, teachers should perhaps be aware of the quality of their TTT and how it is used rather than trying to reduce it to a bare minimum. 


\section{Works Cited}

Brazil, David. Discourse Intonation and Language Teaching. London: Longman, 1980.

Coulthard, Malcolm. Introduction to Discourse Analysis. London: Longman, 1977.

Hunt, Roger. "A Continuing Experiment-Teacher Talking Time and Parent Talking Time." International House-education and Development Journal. 2.14(1996): 23-25.

Krashen, Stephen D. Principles and Practice in Second Language Acquisition. London: Prentice-Hall International, 1981.

Lynch, Tony. Communication in the Language Classroom. London: Oxford University Press, 1996.

Nunan, David. Language Teaching Methodology. London: Prentice Hall, 1991. 